\title{
DETECÇÃO DE RESISTÊNCIA À METICILINA E AOS MACROLÍDEOS EM Staphylococcus aureus ISOLADOS DE JALECO
}

\author{
Isabelle Correa de Moraes, Suzan Leonela Villarroel, Valéria Cataneli Pereira \\ Universidade do Oeste Paulista - UNOESTE, Presidente Prudente/SP. E-mail: suzanleonela@hotmail.com
}

\begin{abstract}
RESUMO
Staphylococcus aureus é uma bactéria patogênica que pode integrar a microbiota humana e ser transferida para equipamentos de segurança individual (EPI) como o jaleco, comumente utilizado por estudantes e profissionais da área da saúde, e serem veiculadas para diferentes ambientes. Visto a importância do estudo da susceptibilidade de $S$. aureus aos fármacos utilizados no tratamento de infecções, este estudo avaliou a sensibilidade à meticilina e aos macrolídeos em $S$. aureus isolados de jalecos de universitários. Foram avaliados $70 \mathrm{~S}$. aureus isolados de jalecos de universitários e $58,5 \%$ foram $S$. aureus resistentes à meticilina (MRSA), carreando o SCCmec tipo I (51,2\%), tipo III $(26,8 \%)$ e tipo IV $(9,7 \%)$. Foram detectados $74,2 \%$ S. aureus resistentes à eritromicina e $25,7 \%$ à clindamicina. Dos isolados que apresentaram resistência a eritromicina, $32,8 \%$ foram positivos para o teste $D$. Os resultados apresentaram taxas elevadas de MRSA e de $S$. aureus resistentes aos macrolídeos em jalecos, ressaltando a importância da adoção de normas de biossegurança entre os universitários.
\end{abstract}

Palavras-chave: Jaleco, MRSA, resistência antimicrobiana, SCCmec, fármacos.

\section{DETECTION OF RESISTANCE TO METHICILLIN AND MACROLIDE IN Staphylococcus aureus ISOLATED COATS}

\begin{abstract}
Staphylococcus aureus is a pathogenic bacterium that can integrate the human microbiota and be transferred to individual safety equipment (EPI), such as the lab coat, which is commonly used by students and healthcare professionals, and is delivered to different environments. A total of $70 \mathrm{~S}$. aureus of college students 'gowns and $58.5 \%$ of college students' gowns were evaluated were $S$. aureus resistant to methicillin (MRSA), carrying SCCmec type I (51.2\%), type III (26.8\%) and type IV (9.7\%). The results were erythromycin resistance, $32.8 \%$ were positive for the $D$ test. The results were statistically significant, indicating that serum levels of MRSA and S. aureus are resistant to erythromycin and $25.7 \%$ to clindamycin. to macrolides in lab coats, emphasizing the importance of adopting biosafety norms among university students.
\end{abstract}

Keywords: White coat, MRSA, antimicrobial resistance, $\mathrm{SCC}$ ecc, drugs.

\section{INTRODUÇÃO}

Staphylococcus é um gênero que abrange bactérias caracterizadas como cocos Grampositivas, imóveis, anaeróbias facultativas e não formadoras de esporos ${ }^{1}$. Os estafilococos dispõem de mecanismos apropriados para colonizar a pele, visto que crescem na presença de altas concentrações de sal e de lipídeos. São facilmente disseminados entre os indivíduos, geralmente através de contato ou fômites, e são capazes de produzir fatores de virulência que promovem a adesão, que impedem a fagocitose e que auxiliam a disseminação no hospedeiro ${ }^{2}$.

$$
\text { A bactéria Staphylococcus aureus, }
$$
encontrada na microbiota humana, em determinadas circunstâncias pode provocar desde simples infecções até as mais graves infecções, sendo considerada a mais virulenta do seu gênero. Sua enorme capacidade de adaptação e resistência à maioria dos antimicrobianos colocou-a atualmente entre as espécies de maior importância nas infecções nosocomiais ${ }^{3}$. 
S. aureus podem ser transferidos para equipamentos de segurança individual (EPI) como o jaleco, comumente utilizado por estudantes e profissionais da área da saúde, e serem disseminados para diferentes ambientes ${ }^{4}$. A contaminação por respingos é muito comum em hospitais e ambulatórios e as roupas são uma importante via de transporte de infecção no ambiente hospitalar. Desta forma, os jalecos dos profissionais da área de saúde, passam a ser o primeiro sítio de contato, sendo considerado um fômite ${ }^{5}$.

Uma vez que muitas Universidades estão ligadas a ambientes hospitalares e laboratórios, os estudantes usam seus jalecos fora de seu local apropriado. $\mathrm{O}$ isolamento de microrganismos em jalecos utilizados pelos profissionais de saúde apresenta possibilidade de contaminação cruzada e disseminação de microrganismos multirresistentes ${ }^{6}$.

Após a descoberta dos antimicrobianos, como a penicilina, infecções que anteriormente tinham um mau prognóstico passaram a ser controladas com sucesso. Contudo, constatou-se o surgimento de determinadas linhagens microbianas resistentes a este fármaco ${ }^{7}$. Desta forma, a meticilina, uma penicilina semissintética, passou a ser utilizada e seu mecanismo envolve a ligação do antimicrobiano com a Proteína Ligadora de Penicilina (PBP). Com a detecção de $S$. aureus resistente à meticilina (MRSA), verificou-se que uma proteína modificada (PBP2a), mediada pelo gene mecA, é a responsável pela baixa afinidade dos betalactâmicos ${ }^{8}$.

As cepas de MRSA produzem uma proteína adicional de ligação à penicilina, conhecida como PBP2a ou PBP2', que tem baixa afinidade para a maioria das penicilinas semisintéticas, são codificados por um gene adquirido, mecA, que foi clonado e sequenciado juntamente com os genes que controlam sua expressão, mecR1 (codificando a proteína transdutora de sinal MecR1) e mecl (codificando a proteína repressora $\mathrm{Mecl})^{9}$.

Um elemento genético que codificava a resistência à meticilina e carregava recombinases únicas específicas do local, designadas como recombinases do cromossoma cassete (ccr) foi subsequentemente identificado e designado como o cromossoma mec da cassete estafilocócica ( $\mathrm{SCCmec)}$. Logo após a descrição inicial do $\mathrm{SCCmec}$, vários elementos $\mathrm{SCCmec}$ estruturalmente diferentes foram descritos. Esses elementos compartilhavam várias características que servem como um alvo para recombinação mediada por ccr. Até o momento estão identificados 13 tipos de $\mathrm{SCCmec}^{9}$.

Já os antimicrobianos macrolídeos induzem a inibição da síntese proteica dependente de RNA, através da ligação em receptores localizados na porção $50 \mathrm{~S}$ do ribossoma, particularmente na molécula $23 \mathrm{~S}$ do RNA, impedindo as reações de transpeptidação e translocação. A resistência pode surgir por: diminuição da permeabilidade da célula ao antimicrobiano, alteração no sítio receptor da porção $50 S$ do ribossoma e inativação enzimática ${ }^{10}$.

As clindamicinas (lincosaminas) agem de forma semelhante, ligam-se exclusivamente a subunidade $50 \mathrm{~S}$ dos ribossomos bacterianos e suprimem a síntese proteica. Agem no mesmo local que a eritromicina e a ligação de um desses antibióticos ao ribossomo inibe a reação do outro ${ }^{11}$.

A resistência aos macrolídeos, lincosaminas e estreptogramina B (MLSB) tem o mecanismo de ação que atua na ligação do ribossomo e inibição da síntese proteica. A resistência do $S$. aureus a estes agentes está relacionada a três mecanismos, modificações no alvo de ligação no ribossomo codificado pelo gene ermA ou ermC conferindo resistência cruzada aos macrolídeos, lincosamidas e estreptogramina B (fenótipo MLSB). Efluxo ativo codificado pelo gene mrsA que confere resistência aos macrolídeos e estreptogramina $B$ e inativação do fármaco ${ }^{12}$.

A resistência MLSB pode ser constitutiva ou induzível, dependendo da exposição aos macrolídeos. $\mathrm{Na}$ expressão constitutiva, a resistência à eritromicina e clindamicina é detectada no antibiograma. Na forma induzível, pode apresentar resistência à eritromicina e falsa sensibilidade à clindamicina. A detecção da resistência induzível pode ser feita pelo chamado D-teste, pelo método de disco aproximação ${ }^{12}$.

Visto a importância do estudo de da sensibilidade de $S$. aureus os fármacos utilizados no tratamento de infecções, este estudo avaliou a susceptibilidade à meticilina e aos macrolídeos em $S$. aureus isolados de jalecos de universitários. 


\section{METODOLOGIA}

\section{Amostras}

Foram analisados 70 S. aureus, já identificados e que foram selecionados aleatoriamente de um estudo prévio que identificou S. aureus em 300 amostras bacterianas de jalecos de alunos de um curso da área de saúde de uma universidade do interior do estado de São Paulo. Essas amostras foram armazenadas a $-70^{\circ} \mathrm{C}$ em caldo nutriente contendo $10 \%$ de glicerol no Laboratório de Microbiologia e Imunologia da universidade.

\section{Detecção da susceptibilidade aos antimicrobianos}

Teste de disco-difusão em Agar

0 teste de susceptibilidade aos antimicrobianos foi realizado pela técnica da difusão da droga em Ágar e os halos lidos a partir de discos impregnados com os fármacos. Para o preparo dos inóculos foram utilizadas culturas em caldo BHI, previamente incubadas por 4 a $6 \mathrm{~h}$ e ajustadas anteriormente com a turbidez da escala 0,5 de McFarland. Os discos utilizados foram: Oxacilina, Cefoxitina, Clindamicina e Eritromicina.

Uma vez ajustada a densidade do inóculo, a semeadura foi feita através de swab esterilizado embebido em inoculo na superfície de Agar Mueller Hinton, e a seguir aplicados os discos impregnados com os antimicrobianos. As placas foram incubadas a temperatura de $35^{\circ} \mathrm{C}$ pelo período de $24 \mathrm{~h}$ (ideal entre 18 e $24 \mathrm{~h}$ ) sendo a atividade do antimicrobiano avaliada pelo diâmetro do halo de inibição através de interpretação em base das normas estabelecidas pelo CLSI (2016).

\section{Determinação e caracterização de MRSA}

Foi realizada a extração do DNA bacteriano através do Kit Illustra, seguindo as recomendações do fabricante. A seguir, foram realizadas reações de $P C R$, com os primers e parâmetros estabelecidos por Murakami et al. ${ }^{8}$. As amostras positivas para o gene mecA foram submetidas às reações de PCR multiplex para a caracterização do $\mathrm{SCCmec}$, utilizando primers e parâmetros estabelecidos por Milheiriço ${ }^{13}$.

\section{Determinação MLSB (Teste D)}

Os isolados resistentes a eritromicina e sensíveis à clindamicina foram submetidos ao D- teste para detectar resistência induzível a clindamicina. Estes foram semeados em ágar Mueller Hinton e um disco de eritromicina foi colocado a uma distância de $20 \mathrm{~mm}$ (borda a borda) do disco de clindamicina, e incubados a $35^{\circ} \mathrm{C}$ por $24 \mathrm{~h}$. A eritromicina presente no disco difunde-se pelo meio de cultura e induz a resistência à clindamicina, resultando em um achatamento do halo de inibição, adjacente ao disco de eritromicina, com a forma da letra $D$ (efeito $\mathrm{D})^{14}$.

\section{Análise dos resultados}

Os testes de avaliação de sensibilidade e especificidade ${ }^{15}$, foram embasados na comparação entre os métodos fenotípicos para detecção de MRSA (disco-difusão com o disco de oxacilina e cefoxitina) e a técnica de PCR, para a detecção do gene mecA, padrão ouro na determinação de MRSA. Os testes aplicados para a avaliação de sensibilidade e especificidade foram assim descritos:

- Sensibilidade (S): proporção de amostras positivas pela técnica de PCR e que foram positivas nos outros métodos fenotípicos.

- Especificidade (E): proporção de amostras negativas pela técnica de PCR e que foram negativas pelos métodos fenotípicos.

\section{RESULTADOS}

Foram estudados $70 \mathrm{~S}$. aureus isolados de jalecos de universitários e 41 (58,5\%) foram MRSA, pela positividade do gene mecA (Figura 1). Os testes fenotípicos detectaram $17(24,2 \%) S$. aureus resistentes a oxacilina e $19(27,1 \%)$ a cefoxitina e a sensibilidade, especificidade estão apresentados na Tabela 1.

Entre os isolados positivos para o gene mecA, 21 (51,2\%) foram do SCCmec I, 11 (26,8\%) foram do SCCmec III e $4(9,7 \%)$ foram do SCCmec IV (Figura 2).

Em relação a eritromicina e clindamicina, foram detectados $52 \quad(74,2 \%) \quad$ S. aureus resistentes à eritromicina e $18 \quad(25,7 \%)$ à clindamicina. Dos isolados que apresentaram resistência a eritromicina, 23 (32,8\%) são positivos para o teste $D$ (Figura 3 ).

A determinação da resistência à eritromicina e clindamicina em MRSA e MSSA (Staphylococcus aureus sensível à meticilina) está apresentada na Tabela 2. 


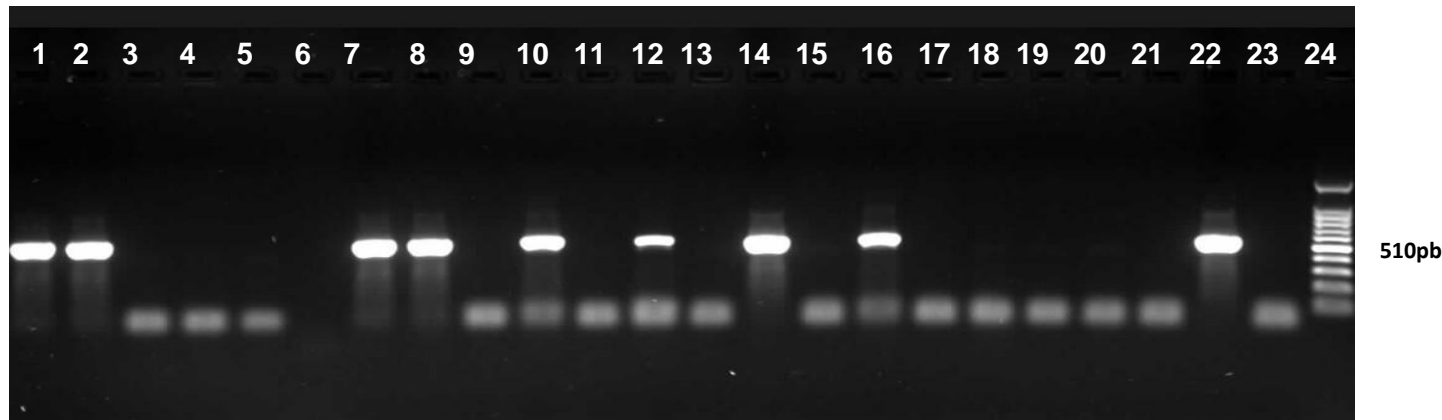

Figura 1. Eletroforese em gel de agarose para determinação do gene mecA (510 bp) em amostras de $S$. aureus pela técnica de PCR. 1, 2, 3, 4, 5, 6, 7, 8, 9, 10, 11, 12, 13, 14, 16, 17, 18, 19, 20, 21 e 22: amostras positivas; 15: amostra negativa; 24: S. epidermidis ATCC 35985 (controle positivo); 23: S. epidermidis ATCC 12228 (controle negativo) e 25: marcador de peso molecular (100 bp).

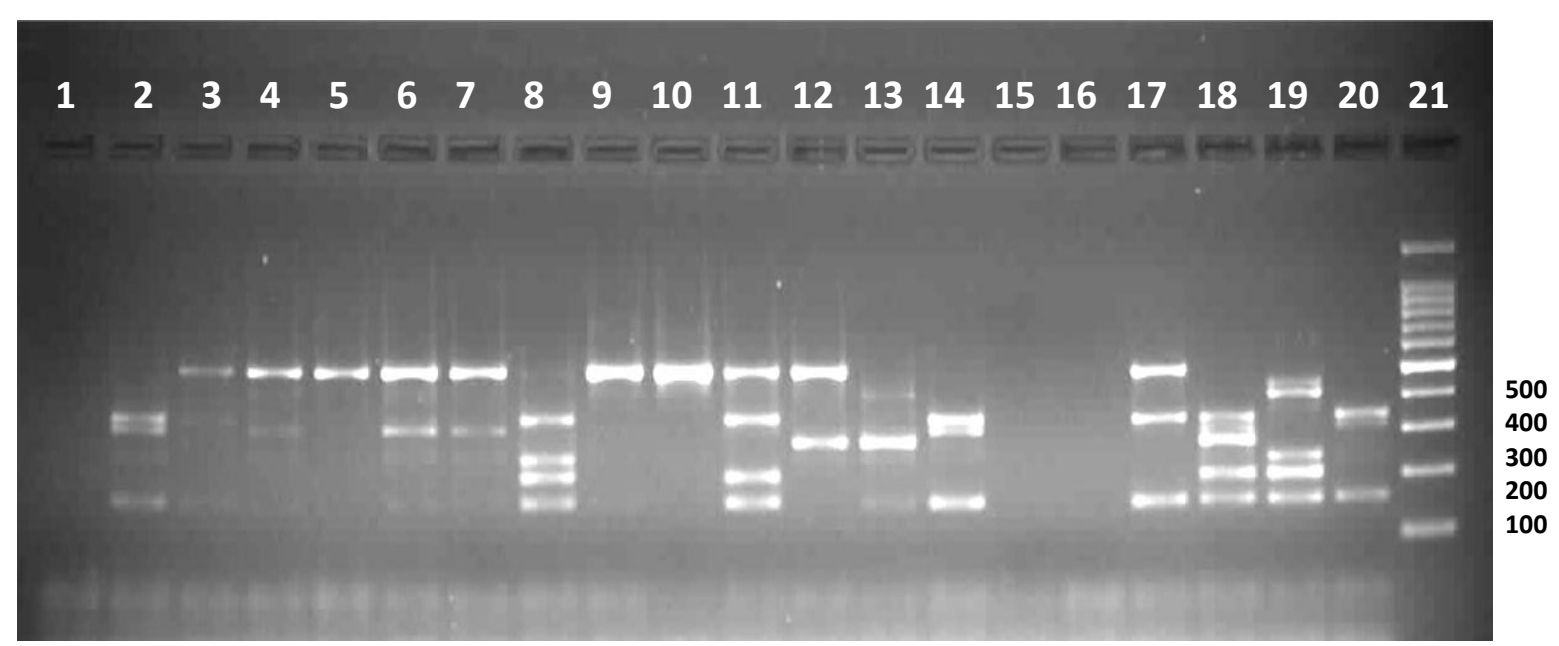

Figura 2. Eletroforese em gel de agarose para determinar dos tipos de cassete cromossômico estafilocócico mec em amostras de S. aureus pela técnica de Multiplex PCR. 3, 4, 5, 6,7 9, 1011 e 12: SCCmec tipo I (342 e 495 pb); 8 e 13: SCCmec tipo III (209, 243 e 414 pb); 2 e 14: SCCmec tipo IV (311 e 342 pb); 15 e 16: não tipadas, 17: COL (SCCmec tipo I); 18: N315 (SCCmec tipo II); 19: ANS46 (SCCmec tipo III); 20: HU25 (SCCmec tipo III); 1: controle negativo; 21: marcador de peso molecular (100 bp).

Tabela 1. Valores de sensibilidade e especificidade métodos fenotípicos para determinação de MRSA em relação a deteç̧ão do gene mecA.

\begin{tabular}{ccc}
\hline \multirow{2}{*}{ Métodos fenotípicos } & \multicolumn{2}{c}{ mecA } \\
\cline { 2 - 3 } Oxacilina & Sensibilidade & Especificidade \\
\cline { 2 - 3 } Cefoxitina & $23 \%$ & $72,4 \%$ \\
\hline
\end{tabular}


Tabela 2. Determinação da resistência à eritromicina, clindamicina e resistência aos macrolídeos (teste D) em relação à detecção do gene mecA e caracterização do SCCmec.

\begin{tabular}{cccccc}
\hline & & \multicolumn{4}{c}{ mecA (+) } \\
\cline { 3 - 6 } & mecA (-) & SCCmec I & scCmec III & SCCmec IV & Não Tipado \\
\hline Eritromicina (R) & $23(79,3 \%)$ & $15(36,5 \%)$ & $5(12,2 \%)$ & $4(9,7 \%)$ & $5(12,2 \%)$ \\
Clindamicina (R) & $7(38,8 \%)$ & $7(63,6 \%)$ & $4(36,3 \%)$ & 0 & 0 \\
Teste D + & $10(43,4 \%)$ & $4(30,7 \%)$ & $2(15,3 \%)$ & $2(15,3 \%)$ & $5(38,4 \%)$ \\
\hline
\end{tabular}

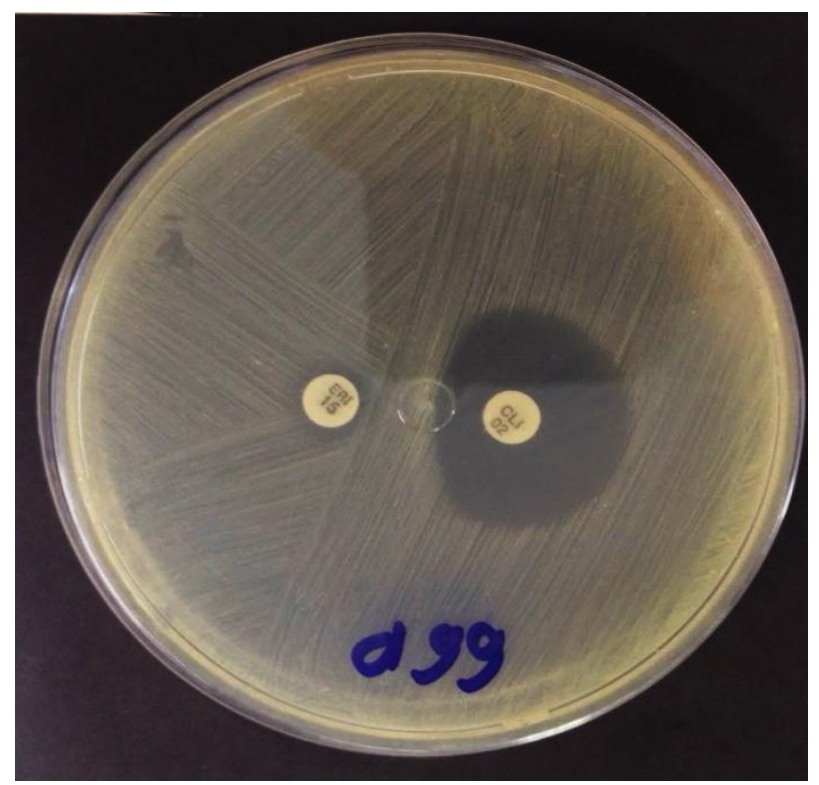

Figura 3. Teste $D$ positivo. Pode-se observar o achatamento do halo do disco de clindamicina na forma da letra $D$, que foi induzido pelo disco de eritromicina.

\section{DISCUSSÃO}

A capacidade do Staphylococcus aureus em se tornar patogênico ao indivíduo é o que traz maior preocupação. Nos últimos anos, a bactéria tornou-se causa cada vez mais acentuada de infecções relacionadas a saúde ${ }^{16}$. A bactéria pode ser transferida para equipamentos de proteção individual (EPI) como o jaleco, comumente utilizado por estudantes e profissionais da área da saúde, e ser veiculado para diferentes ambientes. Assim, este estudo avaliou a resistência à meticilina e a resistência aos macrolídeos em $S$. aureus isolados de universitários da área da saúde.

Foram detectados $58,5 \%$ de MRSA entre os isolados de jalecos, sendo mais elevados quando comparados a outros estudos com o mesmo objetivo. Resultados de Nascimento e Ramos $^{17}$ se assemelham com os deste estudo, enfatizando que a presença de MRSA nestes jalecos uma vez que estes estudantes ainda não frequentaram ambientes hospitalares, sugere que estas cepas são de origem comunitária, principalmente devido ao fato da não relação dos estudantes com ambientes de saúde, que são os locais contaminados em quase sua totalidade por cepas hospitalares.

Os discos de oxacilina e cefoxitina utilizados para a determinação de MRSA apresentaram baixa sensibilidade ( $23 \%$ e $28 \%$ ) e especificidade $(72,4 \%)$, diferentes de um estudo que comparou as técnicas de disco-difusão com a detecção do gene $\operatorname{mec} A$, determinando a sensibilidade de $94,4 \%$ para o disco de oxacilina, 
$100 \%$ para o disco de cefoxitina e especificidade de $98,8 \%$ para ambos discos ${ }^{18}$. Este estudo difere também de um estudo semelhante, ao qual se obteve sensibilidade de $90 \%$, especificidade de $100 \%$ e precisão de $94 \%$. Priya et al. $^{19}$ compararam os resultados fenotípicos e genotípicos de 50 isolados, através de difusão em ágar com disco de oxacilina e de cefoxitina, e PCR multiplex para detectar a presença do gene mecA. O estudo revelou que o uso de cefoxitina é um bom método alternativo para disco de oxacilina pelo método de difusão para a detecção de MRSA, especialmente na identificação de cepas com resistência intermediária a $S$. aureus.

Deve-se salientar que a determinação precisa de MRSA por métodos convencionais é sujeito a variações no tamanho do inóculo, tempo de incubação, temperatura, $\mathrm{pH}$ e concentração de sal, sendo necessário a detecção do gene mecA por métodos moleculares ${ }^{19}$. Atualmente o disco de oxacilina não é preconizado pelo CLSI, que indica a utilização do disco de cefoxitina por apresentar melhor facilidade na leitura ${ }^{20}$. Os resultados genotípicos de mecA são, portanto, o padrão ouro comparado ao fenotípico.

A frequência de isolados resistentes à eritromicina e clindamicina foi maior em MRSA do que em MSSA. Entre os isolados de S. aureus, a resistência induzível aos macrolídeos foi de $32,8 \%$. Houve maior frequência de isolados com - SCCmec I, tanto para eritromicina (36,5\%) quanto para clindamicina (63,6\%). Já isolados com o SCCmec IV apresentou resistência apenas para a eritromicina $(9,7 \%)$ e para os testes $D$ positivos (15,3\%). Oliveira ${ }^{21}$ determinou em seu estudo que a maioria das cepas MRSA abrigando os tipos de mec SCC I, II e III foram resistentes a mais de três outras classes de antimicrobianos não- $\beta$-lactâmicos. Entre tipo de mec SCC IV isolados, eram mais suscetíveis a quase todos os agentes antimicrobianos não- $\beta$-lactâmicos, que é uma característica comum destas. No entanto, quatro isolados abrigando SCCmec tipo IV mostraram resistência a mais de três classes de antimicrobianos, corroborando com este estudo. $O$ aumento da resistência antimicrobiana nas cepas de CA-MRSA e sua disseminação nos ambientes hospitalares que substituem as cepas tradicionais de HA-MRSA ${ }^{22}$, além de diferentes tipos de $\mathrm{SCCmec}$ tanto nos hospitais quanto na comunidade, dificultam as distinções entre elas, mesmo com base no uso de ferramentas moleculares PCR e métodos moleculares baseados em sequência para estudar e compreender sua epidemiologia.

\section{CONCLUSÃO}

A capacidade de Staphylococcus aureus de adquirir genes de resistência é uma preocupação mundial, portanto pesquisas por novas alternativas terapêuticas associadas às políticas de controle do uso de antibióticos e infecções hospitalares, e estudos de vigilância epidemiológica devem ser hábitos constantes entre profissionais de saúde e alternativa para minimizar o problema.

Os dados obtidos neste estudo apresentam altas taxas de colonização de jalecos de estudantes do ensino superior na área de saúde por $S$. aureus multirresistentes, ressaltando a importância das práticas de biossegurança e das técnicas apropriadas de higienização e manutenção do EPI como formas de contenção e controle de infecções. Além disso, as técnicas fenotípicas para determinação de MRSA devem ser analisadas e validadas por técnicas moleculares. Os resultados apresentaram altas taxas de MRSA e de $S$. aureus resistentes aos macrolídeos em jalecos, ressaltando a importância da adoção de normas de biossegurança entre os universitários.

\section{CONFLITOS DE INTERESSE}

Os autores declaram não haver qualquer potencial conflito de interesses que possa interferir na imparcialidade deste trabalho científico.

\section{REFERÊNCIAS}

1. Kloos WETLB. Staphylococcus and Micrococcus. In Murray YPR, Baron EJ, Pfaller MA; Tenover FCRH (Ed.). Manual of Clinical Microbiology. $6^{\text {th }}$ ed. Washington: American Society Microbiology; 1999. p. 264-282.

2. Campiotto LG, Faccin MC, Yamaguchi MU, Kemmelmeier GS. Staphylococcus aureus em profissionais da saúde: prevalência e perfil de resistência aos agentes antimicrobianos. Anais da $V$ Mostra Interna de Trabalhos de Iniciação Científica, CESUMAR, Maringá, PR. 26 a 29 de outubro de 2010.

3. Lima PFM, Borges AM, Parente SR, Junior VCR. 
Staphylococcus aureus e as infecções hospitalares. Rev UNINGÁ. 2015;21(1):32-39.

4. Zachary KC, Bayne PS, Marrison VJ, Ford DS, Silver LC, Hooper DC. Contamination of gowns, gloves, and stethoscopes with vancomycin resistant enterococci. Infect Cont Hosp Epidemiol. 2001;22(1):560-64. DOI: https://doi.org/10.1086/501952

5. Milena C, Siqueira R, Zélia M, Madeira DA, Tapety Fl. Aspectos de biossegurança relacionados ao uso do jaleco pelos profissionais de saúde: uma revisão da literatura. Texto Context Enferm. 2009;18(2):355-60. DOI: https://doi.org/10.1590/S0104-

\section{0}

6. Treakle AM, Thom KA, Furuno JP, Strauss SM, Harris D, Perencevich EN. Bacterial contamination of health care workers' white coats. Am J Infect Cont. 2009;37(2):101-5. DOI: https://doi.org/10.1016/j.ajic.2008.03.009

7. Menezes CHP, Neufeld PM. Bacteriologia e Micologia para o Laboratório clínico. Rio de Janeiro: Revinter; 2006.

8. Murakami K, Minamide W, Wada K, Nakamura $\mathrm{E}$, Teraoka $\mathrm{H}$, Watanabe $\mathrm{S}$. Identification of methicillin-resistant strains of staphylococci by polymerase chain reaction. J Clin Microbiol. 1991;29(10):2240-4.

9. International Working Group on the Staphylococcal Cassette Chromosome elements IWG-SCC. 2012. Acesso em: 5 mai 2018. Disponível em: http://www.sccmec.org/Pages/SCC Classificatio nEN.html

10. Antimicrobianos: bases teóricas e uso clinico. 2012. Acesso em: 5 mai 2018. Disponível em: http://www.anvisa.gov.br/servicosaude/control e/rede $\mathrm{rm} /$ cursos/rm controle/opas web/mod ulo1/macrolideos2.htm

11. Vermelho $A B$, Bastos $M C F$, Sá MHB. Bacteriologia geral. Rio de Janeiro, Guanabara Koogan; 2008.

12. ANVISA. Staphylococcus spp. Resistência aos macrolídeos, lincosaminas e estreptogramina B
(MLSB). Acesso em: 5 mai 2018. Disponível em: http://www.anvisa.gov.br/servicosaude/control e/rede $\mathrm{rm} /$ cursos/boas praticas/modulo4/resis sta4.htm

13. Milheiriço C, Oliveira DC, De Lencastre H. Update to the multiplex PCR strategy for assignment of mec element types in Staphylococcus aureus. Antimicrob Agents Chemother. 2007;51(9):3374-7. DOI: https://doi.org/10.1128/AAC.00275-07

14. Amorim DMR, Person OC, Amaral PJ do, Tanaka II. Resistência induzível à clindamicina entre isolados clínicos de Staphylococcus aureus TT. Mundo Saúde. 2009;33(4):401-5.

15. Curi PR. Metodologia e análise da pesquisa em ciências biológicas. Botucatu: Tipomic; 1997.

16. Fracarolli IFL, Oliveira SA, Marziale MHP. Colonização bacteriana e resistência antimicrobiana em trabalhadores de saúde: revisão integrativa. Acta Paul Enferm. 2017;30(6):651-7. DOI: https://doi.org/10.1590/1982-0194201700086

17. Phellipe J, Nascimento M, Lúcia R, Ramos B. Resistente à meticilina em jalecos de estudantes de enfermagem. Rev Saúde. 2016;12(1):463-9.

18. Pereira VC, Martins A, Rugolo LMS, Cunha MLRS. Detection of Oxacillin Resistance in Staphylococcus aureus Isolated from the Neonatal and Pediatric Units of a Brazilian Teaching Hospital. Clin Med Pediatr. 2009;3(1):23-31. DOI: https://doi.org/10.4137/CMPed.S2085

19. Priya NL, Venkatesh KG, Sumathi G, Geethalakshmi S. Detection of methicillin resistant strains of Staphylococcus aureus using phenotypic and genotypic methods in a tertiary care hospital. Int J Curr Microbiol App Sci. 2017;6(7):4008-14. DOI: https://doi.org/10.20546/iicmas.2017.607.415

20. Broekema NM, Van Tam T, Monson TA, Marshall SA, Warshauer DM. Comparison of cefoxitin and oxacillin disk diffusion methods for detection of mecA-mediated resistance in staphylococcus aureus in a large-scale study. J 
Clin Microbiol. 2009;47(1): 217-9. DOI: https://doi.org/10.1128/JCM.01506-08

21. Oliveira CF, Morey em, Santos JP, LVP Gomes, Cardoso JD, Pinge-Filho $P$ Perugini senhor, Yamauchi LM, YamadaOgatta SF. Molecular e características fenotípicas resistente à meticilina Staphylococcus aureus isolados de pacientes hospitalizados.J infectar Dev Ctries. 2015;9:1-9. DOI:

https://doi.org/10.3855/jidc.5868

22. Costa $A R$, Batistão DWF, Ribas RM, Sousa AM, Pereira O, Botelho CM. Staphylococcus aureus virulence factors and disease. In: Méndez-Vilas A (Ed.). Microbial pathogens and strategies for combating them science, technology and education. Badajoz: Formatex Research Center; 2013. p.702-10.

Recebido para publicação em 17/08/2018

Revisado em 28/08/2018

Aceito em 04/09/2018 